REVISTA ELECTRÓNICA DE RECURSOS EN INTERNET SOBRE GEOGRAFÍA Y CIENCIAS SOCIALES

Universidad de Barcelona

ISSN I578-0007

Vol. XXV. Núm. 26I

I de diciembre de 202 I

DOI: https://doi.org/I0.1344/ara2021.261.36958

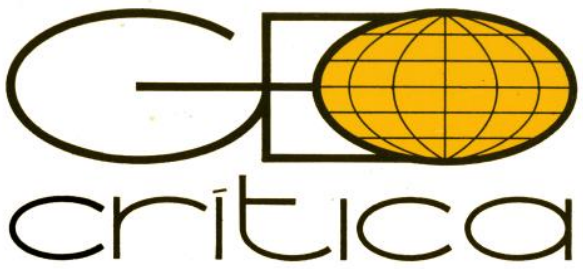

\title{
CAMBIO CLIMÁTICO Y GESTIÓN DEL RIESGO EN EL PROCESO DE ORDENAMIENTO TERRITORIAL EN PERÚ
}

\author{
Sisko Rendón-Cusi \\ Universidad Nacional de San Antonio Abad del Cusco, Perú \\ srendon@unsa.edu.pe
}

\begin{abstract}
Cambio climático y gestión del riesgo en el proceso de ordenamiento territorial en Perú (Resumen)
Actualmente el mundo se enfrenta a un gran desafío en un escenario de inminente aceleración del cambio climático. Según las previsiones, el Perú se encuentra entre los países más vulnerables frente a este problema. Este estudio tiene como objetivo revisar el proceso de iniciativas nacionales enfocadas en la reducción de los impactos del cambio climático. La metodología de estudio consistió en la revisión de las directrices del Plan de Ordenamiento Territorial (POT) y los elementos que lo articulan con las iniciativas de mitigación del cambio climático y gestión de riesgo en el Perú. Del análisis, se observa que existe dispersión de acciones en las diferentes administraciones públicas, ineficiencia en la gestión de los recursos disponibles, burocratización de los procesos, escasa claridad en los objetivos, exiguo interés de los decisores políticos y reducida consciencia de la población frente al problema.
\end{abstract}

Palabras clave: Ordenamiento territorial; Cambio climático; Gestión del riesgo; Integralidad.

Canvi climàtic i gestió del risc en el procés d'ordenament territorial al Perú (Resum)

Actualment el món s'enfronta a un gran desafiament en un escenari d'acceleració imminent del canvi climàtic. Segons les previsions, el Perú es troba entre els països més vulnerables davant d'aquest problema. Aquest estudi té com a objectiu revisar el procés d'iniciatives nacionals enfocades a la reducció dels impactes del canvi climàtic. La metodologia d'estudi va consistir en la revisió de les directrius del Pla d'Ordenament Territorial (POT) i els elements que l'articulen amb les iniciatives de mitigació del canvi climàtic i gestió de risc al Perú. De l'anàlisi, s'observa que hi ha dispersió d'accions a les diferents administracions públiques, ineficiència en la gestió dels recursos disponibles, burocratització dels processos, escassa claredat en els objectius, exigu interès dels decisors polítics i consciència reduïda de la població davant del problema.

Paraules clau: Ordenament territorial; Canvi climàtic; Gestió del risc; Integralitat. 
Climate change and risk management in the process of territorial planning in Peru (Abstract)

The world is currently facing a major challenge in terms of imminent acceleration of climate change. According to forecasts, Peru is among the most vulnerable countries in this scenario. In this study, review the process of national initiatives that aim to reduce the impact of climate change in Peru. The method I employ is to review the directives of the Peruvian Territorial Management Plan (Plan de Ordenamiento Territorial) and the elements that develop it through climate change mitigation and risk management initiatives. The analysis reveals that a variety of actions are being undertaken across the different public administrations; the available resources are being managed inefficiently; processes are being excessively bureaucratized; objectives are obscure; and there is both a lack of interest on the part of political decisionmakers and reduced public awareness of the problems being faced.

Keywords: Territorial planning; Climate change; Risk management; Integrality.

\section{Introducción}

La primera conferencia mundial sobre el clima se realizó el año 1979 en Ginebra (Suiza), con el objetivo de atender la preocupación surgida a raíz de la alta variabilidad y aceleración del proceso de cambio climático en un espacio temporal muy corto. Desde entonces el fenómeno se ha convertido en uno de los focos de interés para la comunidad científica internacional, desarrollándose diversos estudios, monitoreos y reuniones permanentes en todo el planeta. Las investigaciones señalan que las causas de este fenómeno son el uso de combustibles fósiles para la generación de electricidad, los procesos productivos industriales, las actividades agrícolas, de servicio y el transporte, así como la calefacción, refrigeración y cocción de alimentos a nivel domiciliario; constituyen la causa principal del incremento de la proporción de gases de efecto invernadero en particular el $\mathrm{CO}_{2}$ en la atmósfera ${ }^{1}$. Los efectos del cambio climático tienen profundas repercusiones sociales, económicas y ambientales ${ }^{2}$, como se evidencia en las olas de calor, las inundaciones, el incremento del nivel del mar, las sequías, el aumento de especies de flora y fauna en extinción, la destrucción de ecosistemas y la reducción o desaparición de glaciares.

La geógrafa Miriam Zaar $^{3}$ ha realizado un recuento de los principales eventos relacionados con el cambio climático antropogénico y el decrecimiento. En su estudio cita la Primera Conferencia Mundial sobre el Clima en Ginebra en 1979, la creación de World Climate Research Programme en 1980, el Panel Intergubernamental de Expertos sobre el Cambio Climático (IPCC) en 1988 y el informe Planeta Vivo sobre la biodiversidad del planeta, de 1998. Asimismo, destaca la creación del Global Carbón Proyect en 2001, a través del cual se han publicado una serie de investigaciones sobre el incremento de las concentraciones atmosféricas de los principales gases de efecto invernadero. Finalmente destaca la fundación de la Plataforma Intergubernamental CientíficoNormativa sobre Biodiversidad y Servicios de los Ecosistemas (IPBES) en 2010, que busca contribuir a la identificación y priorización de la información científica con el fin de canalizar esfuerzos, generar nuevos conocimientos y fomentar evaluaciones regulares.

\footnotetext{
1 Rodríguez, 2009, p. 59 <https://docplayer.es/8763900-Modulo-3-ordenamiento-territorial-y-gestion-delriesgo.html>.

${ }^{2}$ Ayestarán, $2004<$ https://dialnet.unirioja.es/servlet/articulo?codigo=1158937>.

${ }^{3}$ Zaar, 2021, p. 2 <https://revistes.ub.edu/index.php/aracne/article/view/33232>.
} 
El informe del Grupo Intergubernamental de Expertos sobre el Cambio Climático (IPCC), publicado en 2014 ( $5^{\circ}$ IPCC), ha indicado que los fenómenos extremos relacionados con el clima se intensificarán y que la población tendría que enfrentarse a la escasez de recursos hídricos, a inundaciones, a la caída de la producción alimentaria y a la propagación de enfermedades ${ }^{4}$. En Perú el fenómeno climático más recurrente es El Niño, que en los últimos años se ha presentado con mayor frecuencia e intensidad. Zucchetti y su equipo han demostrado que el Perú es la segunda región del mundo en donde se registran la mayor cantidad de desastres naturales, lo que obliga a la comunidad científica y a las autoridades a proveer a las comunidades locales de los instrumentos y las estrategias necesarias para hacerles frente ${ }^{5}$. Ante este problema el Estado peruano ha aprobado el Plan Nacional de Adecuación al Cambio Climático con un horizonte a mediano plazo marcado en 2030 y otro a largo plazo que se extiende hasta el 2050. Con ello busca reducir los impactos y la vulnerabilidad a través de la planificación territorial y la adecuada gestión de riesgos.

El presente artículo está dividido en seis secciones: en la primera de ellas se caracteriza el estado de los glaciares peruanos; en la segunda se analiza la legislación en torno al fenómeno en una perspectiva temporal definida en tres etapas; en la tercera se analizan los esfuerzos del Ministerio del Ambiente por fomentar iniciativas para la mitigación de los efectos del cambio climático, proceso en el cual ha habido tanto aciertos como desaciertos; en la cuarta se describen las contradicciones existentes en las acciones de mitigación que realiza el Estado peruano a través de los tres niveles de gobierno; en la quinta se explican los esfuerzos de integración y sinergia institucional desarrollados para la gestión del riesgo y el ordenamiento territorial. Finalmente, en la última parte del artículo se presenta las consideraciones finales.

\section{Los problemas que enfrenta Perú}

En Perú el 67\% de los desastres están relacionados con el clima: 5,5 millones de peruanos son vulnerables a lluvias intensas, 2,6 millones están expuestos a sequías y otros 5,6 millones a heladas y friajes ${ }^{6}$, mientras que 14 millones de peruanos sufren problemas asociados con la inseguridad alimentaria ${ }^{7}$. Debido a esto, las normas, planes y actividades estratégicas son factores claves para la mejora de las capacidades de resiliencia y la adaptación social de los sectores más vulnerables.

Los informes del Ministerio de Agricultura y Riego (MINAGRI), emitidos a través de la Autoridad Nacional del Agua (ANA), confirman que el futuro del Perú es preocupante, ya que el país ha perdido el $51 \%$ de su superficie glaciar en los últimos 50 años debido a los efectos del cambio climático. En la actualidad, el Perú cuenta con 18 cordilleras nevadas, dos menos de las

\footnotetext{
${ }^{4}$ Ministerio del Ambiente. 2/4/2014 <https://www.minam.gob.pe/notas-de-prensa/informe-del-ipcc-advierte-riesgosdel-cambio-climatico-en-latinoamerica/>.

${ }^{5}$ Zucchetti et al., 2008, p. 9

$<$ http://www.observatorioubogrd.cl/descargas/MANUAL\%20PARA\%20MUNICIPIOS\%20EN\%20GR.pdf>.

${ }^{6}$ El friaje es un fenómeno meteorológico que ocurre entre el mes de mayo y agosto, debido a la entrada de una borrasca de aire frío desde el océano Pacífico hacia el territorio peruano. Al chocar con la cordillera de los Andes se eleva y genera intensas lluvias y la caída brusca de la temperatura. Para la Organización de las Naciones Unidas para la Alimentación y la Agricultura (FAO) es "una combinación de bajas temperaturas fuera de estación, heladas agronómicas, nieve y granizo que daña los cultivos y pastos en las zonas alto andinas".

7 <https://www.minam.gob.pe/cambioclimatico/wp-content/uploads/sites/127/2018/06/Dossier-NDC.pdf>.
} 
contabilizadas en registros anteriores. El incremento de la temperatura ha acelerado el retroceso de los glaciares y se ha perdido más del $90 \%$ de la superficie glaciar de algunas cordilleras ${ }^{8}$ en las últimas décadas, tal como se aprecia en la figura 1.

Figura 1. Pérdida de superficie glacial en Perú

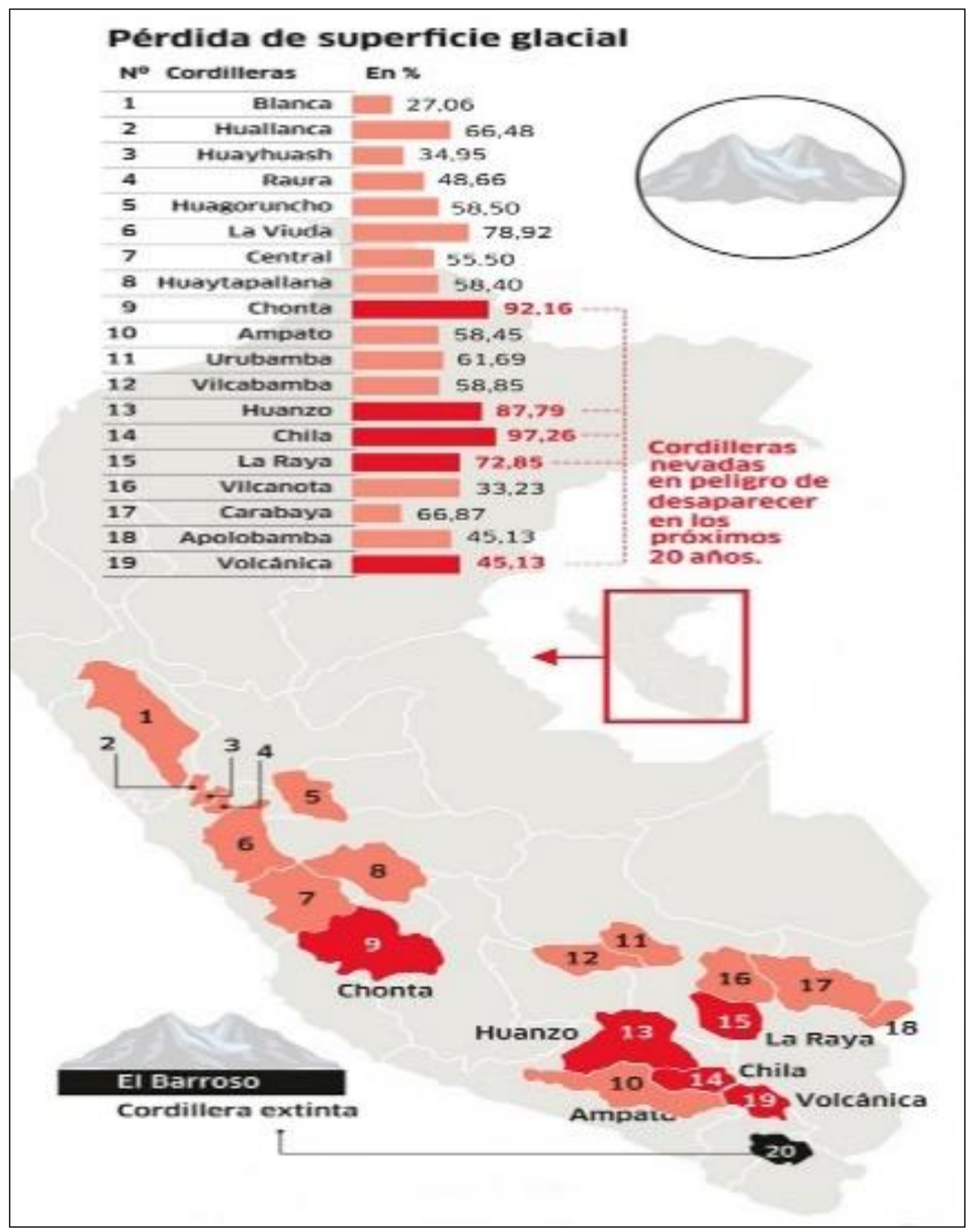

Fuente: A. Mayo, 2016 <https://ambiental.net/2016/08/perdida-de-glaciares-por-cambio-climatico-enperu/>.

\footnotetext{
${ }^{8}$ Autoridad Nacional del Agua (ANA) <http://www.ana.gob.pe/noticia/peru-perdio-el-51-de-sus-glaciares-debido-alcambio-climatico>
} 
A raíz de este diagnóstico, el Estado peruano ha emprendido acciones para generar políticas, planes e instrumentos para la gestión de los impactos del cambio climático ${ }^{10}$. Sin embargo, estas son insuficientes, ya que requieren de un marco político y normativo que integre las estrategias en los procesos de gestión de riesgos y planificación a escala nacional y subnacional. Además, se requiere de sinergias institucionales de ámbito público-privado, que permitan generar las condiciones necesarias para la reducción de impactos y el desarrollo de resiliencia. Entre las políticas y planes estatales están los relacionados con la mejora del "medio ambiente y el entorno rural haciendo hincapié en la gestión del agua, del suelo, de la biodiversidad, el cambio climático, las energías renovables y la vertebración del territorio"11.

El problema de la gestión del recurso hídrico no deriva de la dotación de agua, sino que, según señala Teresa Cabrera, existe una "descomunal asimetría en su distribución territorial, pues menos del $2 \%$ del agua dulce disponible discurre hacia la costa, donde vive más del $70 \%$ de la población nacional. Mientras la Sociedad de Urbanistas del Perú afirma que "la disponibilidad de agua de fuentes superficiales a nivel nacional, se estima en $2.046 .000 \mathrm{hm}^{3}$. En la Vertiente del Pacífico la disponibilidad de agua se estima en $36.660 \mathrm{hm}^{3}$, que representa menos del $1.0 \%$ del total. En la Vertiente del Atlántico la disponibilidad es de $3.769 .000 \mathrm{hm}^{3}$, que corresponde al $99 \%$ del total. Finalmente, en la Vertiente del Titicaca la disponibilidad es de $6.970 \mathrm{hm}^{3}$, equivalente a $0,02 \%$ del total""12 (figura 2).

Las consecuencias de esta desproporción se agravan hacia las cuencas costeras, más aún si tenemos en cuenta que el cambio climático provoca el retroceso de los glaciares, una de las principales fuentes de agua proveniente de la Cordillera Blanca hasta el sur del país ${ }^{13}$. En consecuencia, uno de los aspectos más urgentes frente a este problema es la adecuada gestión de los recursos hídricos a través de la protección de las cabeceras de cuencas y la prevención de la contaminación de los cursos de agua.

\footnotetext{
10 <https://www.minam.gob.pe/wp-content/uploads/2016/05/Tercera-Comunicaci\%C3\%B3n.pdf>.

${ }^{11}$ Martín \& Merinero, 2010, p. 120

<https://www.sistemamid.com/panel/uploads/biblioteca/7097/7128/7129/83506.pdf> .

${ }^{12}<$ https://sinia.minam.gob.pe/documentos/informe-peru-vulnerabilidad-las-ciudades-frente-cambio-climatico-agua .

13 Cabrera, 2012, p. 42 <http://www4.congreso.gob.pe/dgp/didp/boletines/02_2013/imagenes/estado/5PERUHOY2012-DESCO.pdf>.
} 
Figura 2. Relación entre la densidad de la población y la disponibilidad de agua en Perú

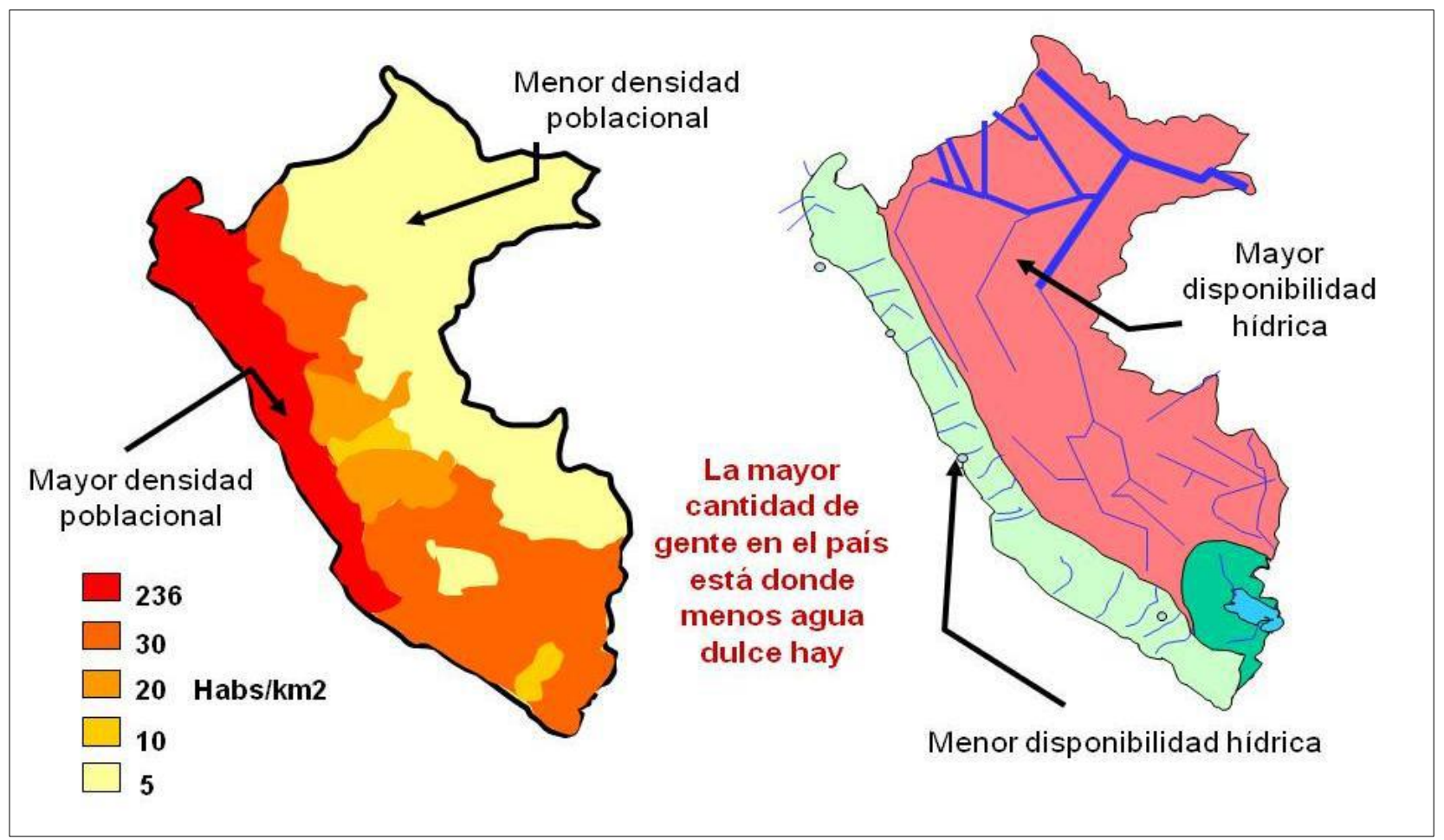

Fuente: Sociedad de Urbanistas del Perú, 2011, p. 8.

Un claro ejemplo del impacto del cambio climático en Perú se manifiesta en la región de Cajamarca, en donde "el agua se ha convertido en una fuente de intensos conflictos por diversas razones como: ineficiencias en los sistemas de gestión del agua, la pobreza, el incremento demográfico y la vulnerabilidad a los riesgos. Asimismo, se advierte escaso conocimiento del potencial hídrico regional y las actividades mineras en cabeceras de cuenca que ponen en riesgo la cantidad y calidad de fuentes de agua" ${ }^{14}$. El marco legal existente en Perú no parece recoger las diferentes realidades del país, dejando en mayor desventaja a las poblaciones pobres, que no son consideradas por las instituciones del Estado al momento de tomar decisiones. Esta situación repercute directamente en las comunidades vulnerables, en donde los "conflictos asociados a la situación de pobreza se ven potenciados por los impactos del cambio climático y el acceso a los recursos básicos"15. Sin embargo, la respuesta estatal es mínima, y se requiere urgentemente la inclusión de políticas ambientales y territoriales orientadas a prevenir desastres naturales. Aunque existen experiencias como la resiliencia agrícola y el uso eficaz de las habilidades y conocimientos tradicionales proporcionados por las organizaciones locales ${ }^{16}$, esto no basta, porque frente a la variabilidad climática se requieren estrategias de desarrollo más eficaces y un proceso sostenido de acompañamiento estatal.

\footnotetext{
${ }^{14}$ Medrano, 2008 <https://zeeot.regioncajamarca.gob.pe/sites/default/files/EstComunicacionZEEOT.pdf>.

${ }^{15}$ Franciskovic \& Godenzi, 2014, p. $258<$ https://repositorio.usmp.edu.pe/handle/20.500.12727/1010>.

${ }^{16}$ Op. cit.
} 


\section{La legislación en torno al fenómeno del cambio climático}

La preocupación por los efectos del cambio climático es universal y el Perú, uno de los diez países que presenta mayor vulnerabilidad frente al problema, ha tomado nota y se ha movilizado para generar normativas dentro del marco de los acuerdos pactados en diferentes foros internacionales y convenios multilaterales. La legislación relacionada con el fenómeno se remonta a la década de los noventa, y, si bien desde la primera ley nacional que menciona "cambio climático" han pasado más de tres décadas, los mayores avances se produjeron a partir de la aprobación de los lineamientos en el Acuerdo Nacional de 2012. En este se acordó fortalecer la gestión territorial en los diferentes niveles de gobierno, así como establecer instancias de gestión integrada del territorio que permitiesen establecer controles, incentivos y otros mecanismos para prevenir, reducir, adaptar o revertir los efectos negativos del cambio climático y remediar o compensar, cuando fuese el caso, los efectos negativos sobre los ecosistemas derivados de la ocupación y uso del territorio ${ }^{17}$. A pesar de esta decisión política, el problema está lejos de haberse mitigado, todo lo contrario, los impactos negativos se han agudizado. Para comprender la generación y evolución del proceso normativo respecto al tema, se han distinguido tres etapas: la primera, de 1990 a 2000, denominada "etapa pasiva"; la segunda, de 2001 a 2010, conocida como "etapa activa"; y la última, de 2011 hasta la actualidad, designada como "etapa proactiva".

\section{Etapa pasiva (1990-2000)}

Después de lo sucedido en el terremoto de Yungay en 1970 -que dejó más de 70.000 muertos- se dio la primera acción legislativa de cara a los desastres ocasionados por la naturaleza. El 29 de marzo de 1972 se promulgó el decreto Ley N ${ }^{\circ}$ 19.338, por medio del cual se creó el Sistema Nacional de Defensa Civil (SINADECI). Franco y Zilbert ${ }^{18}$ señalan que en 1991 se fortalecieron las funciones del Instituto Nacional de Defensa Civil (INDECI), que, adscrito al sector de Defensa, extendió su influencia a las regiones de forma jerarquizada y centralizada. Al mismo tiempo, en esta etapa tomó fuerza la idea de gestión del riesgo, proceso que, aunque fue lento, contribuyó en la mejora de las condiciones de prevención y atención de desastres. En virtud de los acuerdos de la Declaración de Río sobre el Medio Ambiente y el Desarrollo (Rio-ECO92), en Perú se legisló independientemente para cada uno de los procesos (cambio climático, gestión del riesgo y ordenamiento territorial). Hubo avances prácticos en lo relativo a la gestión del riesgo, pero tanto el cambio climático como el ordenamiento territorial se mantuvieron en un plano discursivo.

En 1994 se aprobó la Ley del Consejo Nacional del Ambiente (CONAM), siendo esta una de las primeras legislaciones en mencionar el concepto de clima. Con ello, una de las funciones establecidas para el CONAM fue "conducir la elaboración de la Estrategia Nacional de Cambio Climático, y coordinar la elaboración periódica de los informes nacionales sobre la materia; y presidir las Comisiones Nacionales de los Convenios sobre Cambio Climático, Diversidad Biológica y Fondo para el Medio Ambiente Mundial, en coordinación con las entidades del sector

17 Acuerdo Nacional, 2012 <https://www.acuerdonacional.pe/2016/12/acta-de-la-reunion-no-116-del-foro-delacuerdo-nacional/>.

${ }^{18}$ Franco y Zilbert, 1996. 
público y privado"19. A pesar de los avances legislativos, la prevención y gestión del riesgo quedaron estancados, así como la articulación con otras normativas afines a la temática.

\section{Etapa activa (2001-2010)}

El gobierno transitorio que sucedió al de Fujimori promovió una serie de normas relacionadas con el medio ambiente. En 2001, casi una década después de la creación del Consejo Nacional del Ambiente (CONAM), se aprobó su reglamento -"Reglamento de Organización y Funciones del Consejo Nacional del Ambiente"- que estableció que el CONAM se encargaría del "diseño y dirección participativa de estrategias para la implementación progresiva de las obligaciones derivadas del Convenio de las Naciones Unidas sobre el Cambio Climático y el Convenio de la Diversidad Biológica"20. Durante ese mismo año se aprobó la "Estrategia Nacional de la Diversidad Biológica del Perú", uno de cuyos objetivos estratégicos fue "conocer el impacto del cambio climático sobre la Diversidad Biológica y además investigar la capacidad de protección de las muestras representativas que albergan las áreas protegidas" ${ }^{21}$. Así, con la suficiente evidencia científica existente sobre el problema, el país emprendió acciones de prevención orientadas a la adaptación y mitigación.

En esta década las alarmas a escala internacional empezaron a marcar nuevas pautas y el país se encaminó hacia una etapa activa en la que se aprobaron nuevas leyes orgánicas que incorporaron temáticas ambientales. Destaca la Ley de Gobiernos Regionales, que adscribió como una de sus competencias el "formular, coordinar, conducir y supervisar la aplicación de las estrategias regionales respecto a la diversidad biológica y sobre cambio climático, dentro del marco de las estrategias nacionales respectivas" ${ }^{22}$. También podemos mencionar el Decreto Supremo No0732006 PCM, mediante el cual se creó el "Programa de Reducción de Vulnerabilidades frente al Evento Recurrente de El Niño" (PREVEN). Después de que la situación del fenómeno climático se intensificase, en 2009 se aprobó la polémica "Ley de Recursos Hídricos del Perú", que claramente estaba orientada a la prevención de los efectos del cambio climático, señalando que la Autoridad Nacional, en coordinación con la Autoridad del Ambiente, desarrollaría estrategias y planes para la prevención y adaptación frente al fenómeno ${ }^{23}$.

Finalmente, debemos mencionar que durante este periodo, en 2003, se firmó "La Convención Marco de las Naciones Unidades sobre el Cambio Climático", cuyos objetivos aspiraban a la reducción de los impactos adversos del cambio climático a través de estudios integrados de vulnerabilidad y adaptación, así como por medio del control de las emisiones de contaminantes locales y gases de efecto invernadero (GEI), y a través de programas de energías renovables y de

19 Ley No26.410, 1994. Ley del Consejo Nacional del Ambiente <https://www.minam.gob.pe/wpcontent/uploads/2013/06/ley-general-del-ambiente.pdf>.

20 D.S. No22-PCM, 2001. Reglamento de Organización y Funciones del Ministerio del Ambiente <https://www.minem.gob.pe/_legislacionM.php?idSector=4\&idLegislacion=5247>.

${ }^{21}$ Óp. cit.

22 Ley No27.867, 2003. Ley Orgánica de Gobiernos Regionales <https://www.mimp.gob.pe/ogd/pdf/2014-leyorganica-de-gobiernos-regionales_27867.pdf>.

23 Ley N29.338, 2009. Ley de Recursos Hídricos del Perú <https://leyes.congreso.gob.pe/Documentos/Leyes/29338.pdf> 
eficiencia energética en los diversos sectores productivos ${ }^{24}$. En esta etapa se avanzó en la generación de legislación, pero su puesta en práctica siguió siendo la mayor debilidad en todos los niveles de gobierno, ya que la adaptación y mitigación se realizaron de forma desarticulada, obteniéndose ínfimos resultados.

\section{Etapa proactiva (2011- 2021)}

La tercera etapa se caracteriza por la proactividad, ya que en ella se han desarrollado un mayor número de acciones para la reducción de impactos. A comienzos del periodo, en el año 2011, se

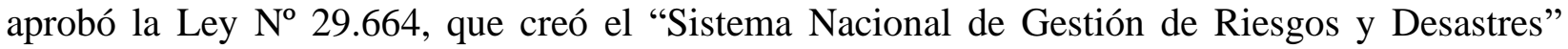
(SINAGERD). Su papel fue coordinar estratégicamente los procesos de gestión del riesgo de desastres en Perú, siendo su órgano público ejecutor el Instituto Nacional de Defensa Civil (INDECI). Esta Ley estableció que el SINAGERD tenía como objetivo:

identificar los peligros, el análisis de las vulnerabilidades y el establecimiento de los niveles de riesgo para la toma de decisiones oportunas en la gestión del riesgo de desastres, la articulación de los componentes y procesos de la gestión del riesgo de desastres, la promoción para la incorporación de la gestión del riesgo de desastres en los procesos de planificación del desarrollo y en el ordenamiento territorial, la prevención y reducción del riesgo, evitando gradualmente la generación de nuevos riesgos y limitando el impacto adverso de los peligros, a fin de contribuir al desarrollo sostenible del país ${ }^{25}$.

Su Reglamento -aprobado en el Decreto Supremo No48-2011-PCM- tuvo la finalidad de establecer y precisar conceptos y mecanismos para identificar y reducir los riesgos asociados, minimizar sus efectos y atender situaciones de peligro mediante lineamientos estratégicos. Un año más tarde y en respuesta al fracaso de las anteriores propuestas legislativas, en 2012, el Estado desarrolló una nueva política nacional de gestión del riesgo de desastres y aprobó el "Decreto Supremo que incorpora la Política Nacional de Gestión del Riesgo de Desastres como Política estatal de obligatorio cumplimiento para las entidades del Gobierno Nacional" 26 . Esta norma estaba considerada de obligado cumplimiento por parte de las entidades del gobierno nacional, en todos sus niveles, y en su artículo $3^{\circ}$ establecía que su implementación se cargaría al presupuesto oficial de las instituciones correspondientes.

Sin embargo, a pesar de estos esfuerzos, se han incumplido la mayoría de los objetivos planteados en las normas e instrumentos y no se ha tenido voluntad política para su concreción. Ninguna de las acciones se ha concretado, manteniéndose en el plano declarativo. Una situación que ejemplifica esta realidad fue la respuesta ante los sucesos que sufrió el país producto de El Niño de 2017. Si bien la legislación indicaba que los gobiernos regionales y locales tenían incorporados los

24 R. Leg. No26.185, 2003. Ratifica la Convención Marco sobre el Cambio Climático de la ONU <http://extwprlegs1.fao.org/docs/pdf/per177635anx.pdf>.

25 Ley N29.664, 2011. Ley que crea el Sistema Nacional de Riesgos de Desastres <https://leyes.congreso.gob.pe/Documentos/Leyes/29664.pdf>.

${ }^{26}$ D.S. No111-2012-PCM. Decreto Supremo que incorpora la Política Nacional de Gestión del Riesgo de Desastres como Política Nacional de obligatorio Cumplimiento para las entidades del Gobierno Nacional <https://www.minam.gob.pe/prevencion/wp-content/uploads/sites/89/2014/10/5.-DS-111-2012-PCM-InCORPORAPOLITCA-NAC-DE-GRD-COMO-POLITICA-NAC.-PLANAGERD-2014-2021.pdf>. 
factores de riesgo en los procesos de planificación y ordenamiento territorial, durante la ocurrencia de los desastres se pudo constatar que todo lo indicado en los instrumentos era letra muerta. Los objetivos de planes e instrumentos han quedado en la retórica y no se ha concretado la ejecución ni se han corregido las acciones, sino que la tendencia recurrente tanto en los políticos como en la población es el olvido y, con ello, la escasa asimilación de los desastres, que vuelven a repetirse debido a que las diferentes instancias carecen de memoria en temas relacionados con los riesgos naturales.

A raíz de los desastres ocurridos en los últimos años, el Estado peruano ha aprobado normativas específicas relacionadas con la gestión de riesgos (D.S. No 111-2012-PCM.), el cambio climático (Ley $\mathrm{N}^{\mathrm{o}}$ 30.754), el ordenamiento territorial (R.M. $\mathrm{N}^{\mathrm{o}}$ 135-2013-MINAM) y el reasentamiento poblacional para zonas de muy alto riesgo no mitigable ${ }^{27}$ (Ley $\mathrm{N}^{\circ} 29.869$ ). No obstante, para este último caso, por más que existan normativas para resolver los problemas de vivienda en zonas de alto riesgo, la realidad es compleja, porque se incrementan los asentamientos de infraviviendas en la periferia de las grandes ciudades de la costa debido al continuo aumento de la población, que ha pasado de 18.364.747 habitantes en 2012 hasta los 21.092.624 habitantes en 2021.

En los últimos años se han desarrollado procedimientos relacionados con el Plan de Ordenamiento Territorial (POT), cuya primera fase fue el proceso de Zonificación Ecológica y Económica (ZEE). Hasta el año 2013, el instrumento no consideraba la gestión de riesgo ni el cambio climático, y su incorporación posterior produjo el incremento de fases y etapas en el Plan de Ordenamiento Territorial, aumentando también el tiempo necesario para lograr los planes, que se volvieron complicados de alcanzar. Con la inclusión de Estudios Especiales y en particular del "Estudio de evaluación del riesgo de desastre y vulnerabilidad al cambio climático" en el proceso del POT, se buscaba:

"identificar elementos vulnerables, susceptibles de ser afectados por las diferentes manifestaciones de este fenómeno; contar con un instrumento básico que permita tomar decisiones y realizar acciones de prevención, mitigación y adaptación ante eventos de desastres, vinculados o no al efecto del cambio climático; y mejorar la comprensión de las conexiones entre los procesos de generación de conocimiento técnico-científico de los fenómenos (naturales o antrópicos), el ordenamiento territorial y la gestión de riesgo de desastres" 28 .

Se puede observar que existe un patrón común entre los objetivos que persiguen la gestión del riesgo, la mitigación del cambio climático y el ordenamiento territorial, sin embargo, en la praxis se presentan como procedimientos confusos, completamente desvinculados, que en definitiva provocan que no haya logros destacables. El gobierno de Pedro Pablo Kuczynski realizó, en 2017, una reforma institucional por medio de la formulación de un nuevo Reglamento de Organización de Funciones (ROF) del Ministerio del Ambiente. Los cambios acometidos no han contribuido a mejorar las sinergias institucionales, sino todo lo contrario, han generado vacíos en el proceso de

\footnotetext{
${ }^{27}$ Ley No29.869 <https://leyes.congreso.gob.pe/Documentos//ExpVirPal/Normas_Legales/29869-LEY.pdf〉.

28 R.M. N¹35-2013-MINAM, 2013. Guía metodológica para la elaboración de los instrumentos técnicos sustentantorios para el ordenamiento territorial <https://www.minam.gob.pe/ordenamientoterritorial/wpcontent/uploads/sites/129/2017/02/08.-Guia-Metodologica-RM-135-2013-MINAM.pdf>.
} 
Cambio climático y gestión del riesgo en el proceso de ordenamiento territorial en Perú

ordenamiento territorial, que ha quedado relegado, poniendo en duda la eficacia de la reforma y sus objetivos ${ }^{29}$.

\section{El Ministerio del Ambiente y el cambio climático en Perú}

Desde la creación del Consejo Nacional del Ambiente (CONAM) hasta su consolidación institucional en el actual Ministerio del Ambiente (MINAM), se han sucedido años de debate y discurso político en torno al problema ambiental. En la actualidad, en el seno de este Ministerio existe una unidad exclusiva orientada al cambio climático, la Dirección General de Cambio Climático y Desertificación (DGCCD). En el año 2009, el Ministerio del Ambiente propuso una "Guía para el Ordenamiento Territorial en Perú" que consideraba el cambio climático como "un peligro actual para el planeta y particularmente para el país", y que planteaba "tomar conciencia de este cambio en las condiciones básicas de vida y actuar proactivamente para adecuar los usos y la ocupación del territorio a semejante reto"30. Un año más tarde, en 2010, el Ministerio del Ambiente presentó el "Plan de acción de adaptación y mitigación frente al cambio climático", instrumento que delineaba una serie de objetivos:

1. Diseñar e implementar un Sistema de Monitoreo participativo del comportamiento del cambio climático en la Amazonía. El sistema de monitoreo deberá ser diseñado, implementado y operado de manera participativa con las organizaciones de los pueblos indígenas de la Amazonía.

2. Diseñar e implementar la red de estaciones meteorológicas a nivel de cuencas y zonas de vida, involucrando a los pueblos indígenas de la Amazonía en la toma de datos, procesamiento, interpretación y difusión de los indicadores del sistema de cambio climático; el cual deberá considerar la cosmovisión indígena, para proyectar escenarios futuros de comportamiento de los ecosistemas.

3. Diseñar e implementar programas de capacitación en cambio climática; considerando el enfoque intercultural a fin de sensibilizar y fortalecer las capacidades de los profesionales de los sectores del estado y a los pueblos indígenas de la Amazonía en la mitigación y disminución de los efectos del cambio climático ${ }^{31}$.

Dada la escasa aplicación de las medidas legislativas comentadas en el apartado anterior, cabe preguntarse si en este caso se cumplieron o no los objetivos propuestos. Si volvemos a tomar como ejemplo el fenómeno de El Niño de 2017 cuyos efectos fueron destructores para el país, podemos afirmar que no se cumplieron los objetivos planteados, ya que no hubo ningún tipo de respuesta estratégica frente al problema. Los daños causados siguen latentes y la reconstrucción ha sido un proceso lento, costoso, plagado de corruptelas. ¿Dónde han quedado las medidas de acción y prevención elaboradas por el Estado? Probablemente no fueron suficientes, se hicieron sin

\footnotetext{
${ }^{29}$ D.S. Nº02-2017-MINAM, 2017. Aprueban el reglamento de organización y funciones (ROF) del Ministro del Ambiente <https://www.minam.gob.pe/wp-content/uploads/2017/04/D.S-N\%C2\%B0-002-2017-MINAM1.pdf>.

${ }^{30}$ R.M. Nº135-2013-MINAM. Guía metodológica para la elaboración de los instrumentos técnicos sustentatorios para el Ordenamiento Territorial <https://www.minam.gob.pe/ordenamientoterritorial/wpcontent/uploads/sites/129/2017/02/Gu\%C3\%ADa-Metodol\%C3\%B3gica.pdf>.

${ }^{31}$ MINAM, 2010, p. 15 <ttps://sinia.minam.gob.pe/documentos/plan-accion-adaptacion-mitigacion-frente-cambioclimatico>.
} 
planificación, con una gestión deficiente, centralizada, destinando escasos recursos a los gobiernos regionales y locales.

Recientemente el Ministerio del Ambiente ${ }^{32}$ ha incorporado el análisis del riesgo natural y antrópico en las medidas de adaptación al cambio climático, dentro de los procesos de ordenamiento territorial ${ }^{33}$, con lo que busca identificar elementos vulnerables, susceptibles de ser afectados por las diferentes manifestaciones de este fenómeno. Por lo general, los riesgos tienen dos componentes básicos: los producidos por la naturaleza, derivados de una "crisis ecológica", y los producidos como consecuencia de acciones antrópicas, sean estas de carácter social, ambiental y/o económico. Para poder reducirlos, el geólogo Gustavo Aguirre plantea que la evaluación de riesgos no debe perder la perspectiva de una valoración cualitativa, indirecta y de carácter predictivo $^{34}$. Siguiendo esta lógica, el Ministerio del Ambiente ha elaborado un mapa de susceptibilidad física del Perú ${ }^{35}$ (figura 3), que consiste en un "instrumento técnico generado a partir de información física que identifica las zonas propensas a inundaciones y deslizamientos en la costa y sierra del país frente al suceso de eventos hidrometeorológicos, determinando la probabilidad de ocurrencia muy alta en el $40 \%$ y alta en el $60 \% " 36$.

La iniciativa estatal buscó proveer de información relevante para una adecuada planificación del territorio y para la prevención de desastres mediante la evaluación multivariable. La elaboración de estos mapas representó un avance importante, pero a escala de los gobiernos locales no ha tenido un impacto positivo y su utilización es nula, debido a que estos organismos no cuentan con capacidades técnicas para acceder a la información entregada, como los mapas, y, a partir de ellos, realizar acciones preventivas que reduzcan el impacto de los riesgos naturales. A pesar de estas deficiencias, se debe mencionar la importancia de avances puntuales, como el estudio de evaluación del riesgo de desastres y vulnerabilidad al cambio climático en las provincias de Pachitea, Puerto Inca, Huánuco, Leoncio Prado y Marañón, así como estudios similares en las regiones de Piura, Cusco, Tacna y Ayacucho ${ }^{37}$.

\footnotetext{
${ }^{32}$ MINAM, 2016, p. 90. <https://sinia.minam.gob.pe/documentos/ordenamiento-territorial-ot-peru-2011-2015>

${ }^{33}$ Rendón, 2019. <https://www.tesisenred.net/handle/10803/668162\#page=1>

${ }^{34}$ Aguirre, 2005, p. 394. <https://www.bage.age-geografia.es/ojs/index.php/bage/article/view/2023/1936>

35 <https://www.minam.gob.pe/wp-content/uploads/2017/01/MAPA-DE-SUSCEPTIBILIDAD-FISICA.pdf>

${ }^{36}$ MINAM, 2016, p. 252.

${ }^{37}$ Op. Cit., p. 145.
} 
Cambio climático y gestión del riesgo en el proceso de ordenamiento territorial en Perú

Figura 3. Mapa de susceptibilidad física de zonas propensas a inundaciones y deslizamientos en la costa y sierra frente a la ocurrencia de eventos hidrometeorológicos extremos

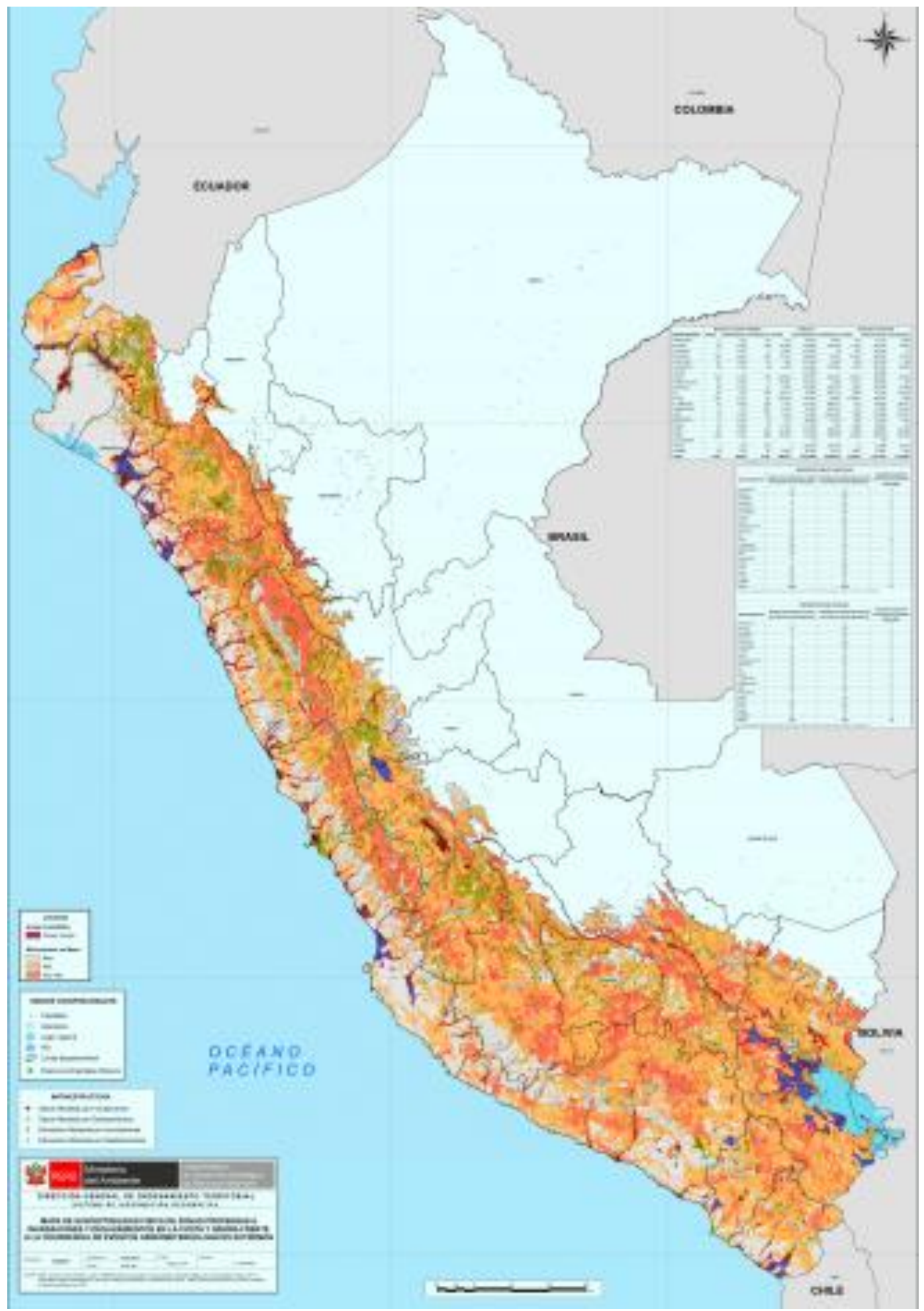

Fuente: DGOT- MINAM, 2011 
Es necesario destacar los criterios planteados para los diferentes estudios, puesto que se "analiza la vulnerabilidad a través de la exposición, fragilidad y resiliencia, de tres elementos importantes como son, la población, medios vitales y actividades económicas, resultado de estas dos variables" ${ }^{39}$. A esto se suma que otras instituciones no gubernamentales también han desarrollado guías metodológicas, herramientas fundamentales para orientar a los gobiernos regionales y locales en la implementación de los planes de ordenamiento territorial y la gestión de riesgos ${ }^{40}$. El geólogo Gustavo Aguirre señala que "la identificación y la evaluación de los riesgos naturales y tecnológicos deben constituir un documento básico en la ordenación del territorio"41, por lo que los instrumentos de ordenamiento territorial constituyen herramientas imprescindibles para la gestión del riesgo y el desarrollo.

Por otro lado, Anna Zucchetti ${ }^{42}$ y otros autores ponen énfasis en el hecho de que el territorio peruano está asentado sobre tres placas tectónicas activas que forman parte del "Anillo de Fuego del Pacífico", donde se produce el $80 \%$ de la actividad sísmica y volcánica de la Tierra, por lo que el país está propenso a sufrir terremotos, deslizamientos, tsunamis y erupciones volcánicas. A esto se suma el precario proceso de ocupación y desarrollo de las ciudades, que no cuentan con planes de desarrollo urbano adecuados y están expuestas a riesgos y peligros naturales. Los problemas no solo son de carácter natural, sino también de carácter antrópico. Un ejemplo de esto lo observamos en la mina de Las Bambas, ubicaba en la provincia de Cotabambas (Apurímac), donde el transporte permanente de concentrado de cobre, considerado mercancía peligrosa, a otra mina en la provincia de Espinar (Cusco), genera una constante contaminación ambiental que afecta a numerosas comunidades campesinas de Cotabambas y Chumbivilcas. Si bien el país cuenta con una amplia normativa ambiental, en este caso no se han tomado medidas correctivas para disminuir el peligro y la contaminación de transporte por carretera, sin que se haya hecho efectiva la legalidad vigente. Al contrario, la actuación estatal ha sido residual frente a los problemas y no se ha aplicado los Instrumentos de Gestión Ambiental (IGA) en la toma de acciones inmediatas frente a hechos que han puesto en peligro a la población y su entorno.

El Ministerio del Ambiente ha desarrollado un "estudio detallado de forma cuantitativa y cualitativa de los niveles de riesgo por provincia [...] se han desarrollado los modelos que determinan el nivel de riesgo existente y se han formulado las recomendaciones respectivas para la reducción del riesgo de desastres" 43 . Sin embargo, según Zucchetti y sus colaboradores sería necesario agregar a estas evaluaciones "temas fundamentales como análisis de vulnerabilidad, medidas de prevención, sistema de alerta temprana, respuesta de la ayuda, coordinación de la ayuda y puesta en marcha del proceso de reconstrucción" 44 , factores que no solo deben estar contenidos en el papel, sino que deben tomarse en cuenta en acuerdos con la participación de todos los actores que forman parte de la sociedad civil organizada. Además, deberían incorporarse acciones de prevención llevadas a cabo a través de "temas transversales como criterios de ordenamiento territorial, principios de participación pública y ciudadana, gobernabilidad, enfoque de equidad de género, e inclusión de la diversidad cultural" 45 . Todos estos elementos deben ser tomados en cuenta

\footnotetext{
${ }^{39}$ Op. Cit., p. 146.

${ }^{40}$ Op. Cit., p. 9.

${ }^{41}$ Op. Cit., p. 393.

42 Op. Cit.

${ }^{43}$ Op. Cit., p. 146.

${ }^{44}$ Op. Cit., p. 81.

${ }^{45}$ Op. Cit.
} 
Cambio climático y gestión del riesgo en el proceso de ordenamiento territorial en Perú

en la planificación y ordenación del territorio, siendo "de primordial importancia, que los riesgos existentes sean valorados, y que dicha valoración pueda cartografiarse a una escala apropiada, para conseguir una visión espacial de las zonas más vulnerables y aquellas más seguras del territorio a ordenar" 46 .

Teóricamente, los proyectos de inversión pública y privada cuentan con análisis de riesgos ambientales y sociales, pero, por la forma como se elaboran los perfiles y los expedientes técnicos, estos aspectos no dejan de ser más que consideraciones burocráticas, sin que se tome en cuenta su real importancia. Los sectores comprometidos con el problema realizan esfuerzos en la elaboración de mapas de la susceptibilidad física del Perú, por ejemplo, de zonas propensas a inundaciones y deslizamientos de tierra en la costa y en la sierra producto de la ocurrencia de eventos hidrometeorológicos extremos, como lo ocurrido en la periferia de Lima en $2017^{47}$ (figura 4).

Figura 4. Efectos de las inundaciones de Huachipa (Lima) provocadas por el fenómeno de "El Niño" de 2017

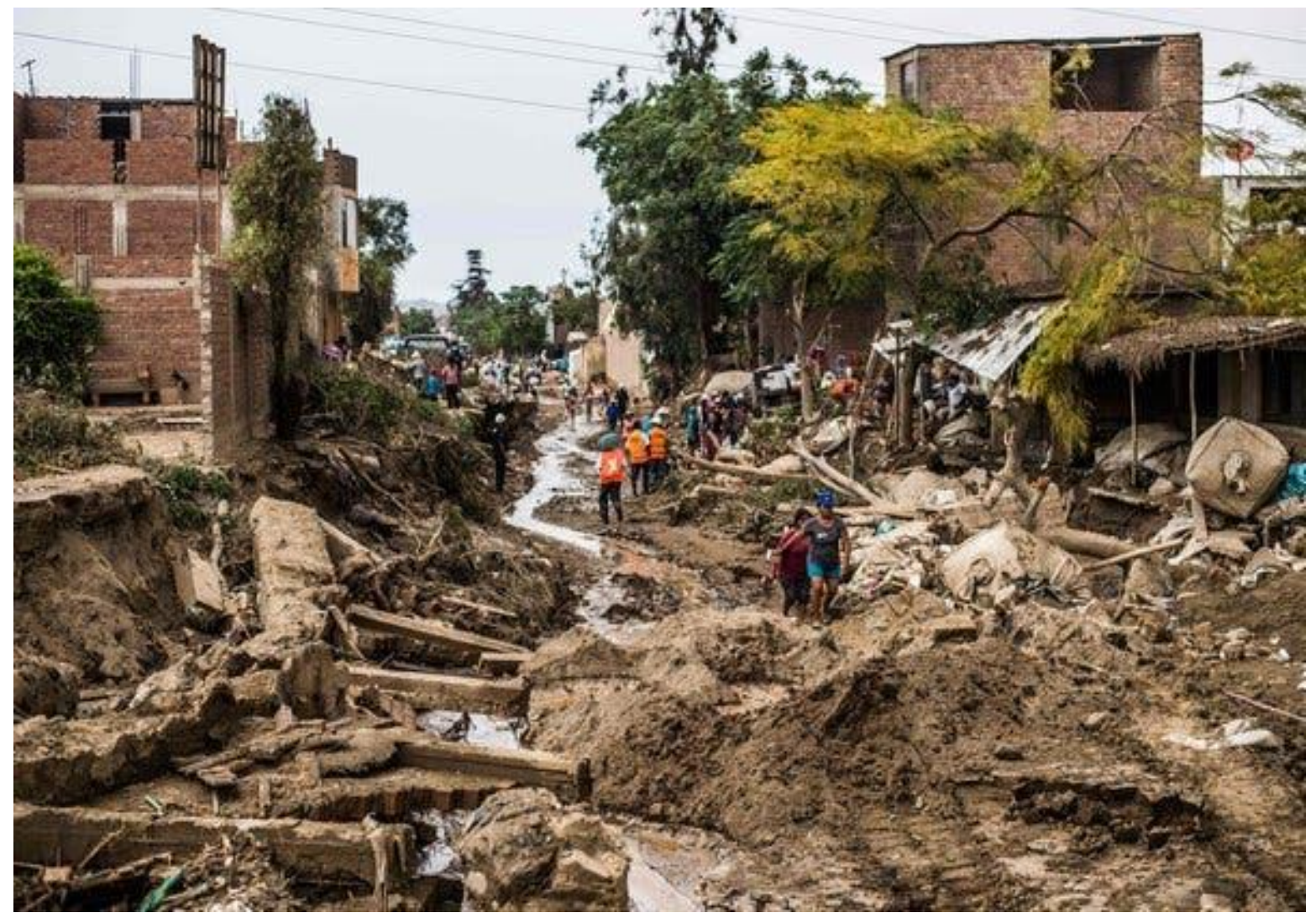

Fuente: <https://www.nytimes.com/es/2017/04/07/espanol/america-latina/deslaves-america-del-sur-barbablanca.html>.

\footnotetext{
${ }^{46}$ Op. Cit., p. 394.

${ }^{47}$ <https://www.nytimes.com/es/2017/04/07/espanol/america-latina/deslaves-america-del-sur-barba-blanca.html>
} 
El Ministerio del Ambiente señala que el mapeo elaborado "contiene y reporta información técnica de las características naturales del territorio (susceptibilidad física del territorio), peligros de origen natural inventariados de manera cualitativa y cuantitativa, y elementos de ocupación socioeconómica del territorio que permiten ubicar las zonas de mayor probabilidad de afectación si ocurriese un evento hidrometeorológico extremo" 48 . Pese a ello, no se reportan logros relevantes y cada desastre natural no genera más que damnificados.

El Sistema Nacional de Gestión del Riesgo de Desastres considera la importancia del mapa de riesgos, ya que las "características físicas andino-pacificas del país exigen una absoluta prioridad de los mapas de riesgo con previsiones ante terremotos y tsunamis. Los problemas de deslizamientos y subsidencia en las vertientes andinas necesitan cartografiarse", como señala el geógrafo español Vicente Bielza de Ory ${ }^{49}$. Es por ello que se han realizado mapeos en regiones que presentan un mayor riesgo, como la ciudad de Arequipa, donde un grupo de geólogos ha evaluado los peligros derivados de su ubicación al pie del volcán Misti, con el objetivo de brindar al Gobierno de la Región, a la Municipalidad Provincial de Arequipa y a otras instituciones un documento base para el manejo de una posible crisis volcánica ${ }^{50}$. En este caso, los resultados del mapa de susceptibilidad nos presentan información geo científica que contribuye, de manera general, en la planificación territorial, y de manera puntual en la elaboración de planes de acción para el tratamiento de las áreas críticas identificadas.

\section{Contradicciones en las políticas de mitigación}

La geógrafa María Cuesta advierte que se han rebasado todos los límites éticos para justificar la destrucción de los recursos naturales debido al empleo de tecnologías dañinas para la sociedad y para el medio ambiente, en nombre del progreso. "Esta dinámica globalizadora e injusta ha conducido a enormes desigualdades sociales entre el ámbito rural y urbano, entre regiones ricas y pobres, entre centros y periferias" ${ }^{" 51}$. En Perú, basta enumerar los derrames de petróleo, la deforestación de la Amazonía y la contaminación de ríos y lagunas alto andinas, como ejemplos evidentes de los vacíos en la política medioambiental.

Las políticas promovidas por parte del Estado generan dudas sobre su eficacia, ya que el modelo de desarrollo nacional está atrapado en una ecuación compleja entre el crecimiento y los recursos naturales. Por un lado, en forma dispersa se promueven políticas de mitigación y adaptación al cambio climático, la gestión de riesgos y el ordenamiento territorial, y, por otro, se impulsa la acelerada expansión de actividades extractivas en los Andes y la Amazonía, en particular de la minería. De Echave, Hoetmer y Palacios señalan que los procesos extractivos como la minería ocasionan grandes consecuencias negativas a nivel ecológico y social, ya que están produciendo impacto sobre el acceso al agua de las comunidades alto andinas, lo que se ve agravado si se

\footnotetext{
${ }^{48}$ Op. Cit., p.147

${ }^{49}$ Bielza de Ory, 2012, p. 99. <https://www.jstor.org/stable/43558256?seq=1>

${ }^{50}$ Mariño et al., 2006.

<https://repositorio.ingemmet.gob.pe/bitstream/20.500.12544/441/2/Evaluacion_de_peligros_volcanicos_mapa_de_ peligros_volcan_Misti.pdf $\rangle$

${ }^{51}$ Cuesta, 2006, p. $260<$ https://www.bage.age-geografia.es/ojs/index.php/bage/article/view/575>.
} 
Cambio climático y gestión del riesgo en el proceso de ordenamiento territorial en Perú

considera la rápida destrucción de los glaciares andinos ${ }^{52}$. De igual manera, la industria de los hidrocarburos ha tenido un profundo impacto en la Amazonía ${ }^{53}$ debido al derrame de petróleo en los ríos de la región, el último de los cuales se produjo en junio de $2019^{54}$ (figura 5). Además, generan una presencia antrópica en zonas de selva prístina e intervienen en la deforestación de importantes áreas.

Figura 5. Derrame de petróleo en la región Loreto, Perú

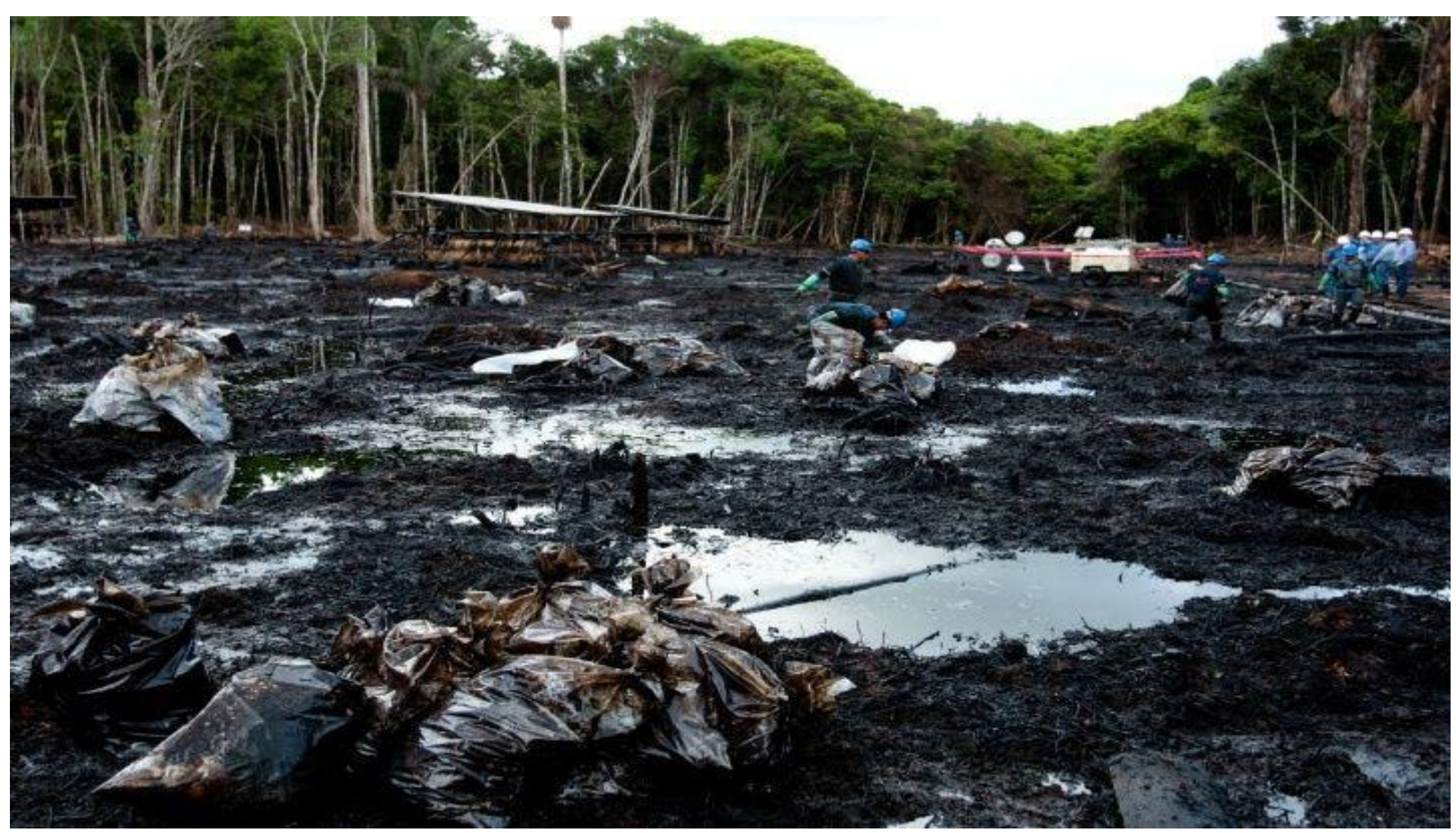

Fuente: 〈https://www.biodiversidadla.org/Noticias/Emergencia-en-el-Amazonía-por-terrible-derrame-de-petroleo>.

Si bien la minería es una actividad importante para la economía nacional debido a la gran inversión y el empleo que genera en el país, es inaceptable el incumplimiento de la normatividad ambiental ante la indiferencia o la acción ineficaz del Estado. Cabe hacerse la pregunta de si es posible construir contrapesos democráticos frente al despliegue del poder económico, político, social y territorial de la minería, interrogante a la que Mendoza, Passuni y Echave responden diciendo que "una primera tarea para construir contrapesos democráticos es enfrentar las enormes resistencias que existen en el país a los intentos de reforma de las políticas públicas vinculadas, directa o indirectamente, a la problemática minera" ${ }^{55}$, siendo un aspecto de enorme debilidad en las decisiones políticas de los poderes del Estado.

\footnotetext{
${ }^{52}$ De Echave, Hoetmer, \& Palacios, 2009 <http://cooperaccion.org.pe/publicaciones/mineria-y-territorio-en-el-peruconflictos-resistencias-y-propuestas-en-tiempos-de-globalizacion/>.

${ }^{53}$ Bebbington y Bury, 2010 <https://dialnet.unirioja.es/servlet/articulo?codigo=5042120>.

${ }^{54}<$ https://www.biodiversidadla.org/Noticias/Emergencia-en-el-Amazonia-por-terrible-derrame-de-petroleo>.

${ }^{55}$ Mendoza, Passuni, \& De Echave, 2006, p. $32<$ https://redextractivas.org/download/la-mineria-en-el-sur-andino-elcaso-de-cusco-cooperaccion-2015/>.
} 
Según la Tercera Comunicación Nacional del Perú a la Convención Marco de las Naciones Unidas sobre el Cambio Climático, se han realizado grandes acciones cuyos resultados son sorprendentemente positivos ${ }^{56}$, destacando los avances en la gestión de emisiones de gases de efecto invernadero, en la adaptación al cambio climático y al estado de la vulnerabilidad, en educación, sensibilización, fortalecimiento de capacidades y generación de información para la gestión y el financiamiento. Sin embargo, la realidad evidencia todo lo contrario, y la perfección que señala el documento contrasta con hechos como la deforestación de la Amazonía a causa de la minería ilegal y los niveles de vulnerabilidad en que queda la población frente a este problema. Dourojeanni afirma que si no se ha puesto freno a la deforestación y la degradación del bosque, tampoco se ha aprovechado la oportunidad de mitigar los impactos del cambio climático ${ }^{57}$.

Como ya hemos señalado, el Ministerio del Ambiente promueve un proceso de ordenamiento territorial como una estrategia para reducir efectos negativos a través de la Zonificación Ecológica Económica, que define zonas potenciales o con limitaciones para la ejecución de proyectos de desarrollo y zonas de alto riesgo ${ }^{58}$. Sin embargo, en dos décadas de implementación de este proceso no se han logrado resultados, excepto una serie de contradicciones y debilidades en su concepción y metodología, lo que ha provocado el desencanto en los gobiernos subnacionales. A pesar de que en las últimas décadas se han logrado innegables avances a nivel legislativo, lamentablemente gran parte de esta legislación ha quedado en el papel y ha generado escasos cambios en el diseño y aplicación de las políticas e inversiones ${ }^{59}$, lo que evidencia diferencias y contradicciones entre el discurso de los gobiernos de turno y las acciones generadas.

En este escenario incierto queda un largo camino por recorrer. Tal como manifiesta el geógrafo Horacio Capel, "estamos al borde de la catástrofe, por el calentamiento y el cambio climático, por la contaminación química, por la degradación del ambiente" ${ }^{60}$. En Perú, la Política Nacional del Ambiente presenta algunos lineamientos para la "mitigación y adaptación al cambio climático", y en cuanto a la integración, esta hace hincapié en "incorporar en los procesos de ordenamiento territorial el análisis del riesgo natural y antrópico"61. Con el fin de hacer efectivas estas políticas, en 2013 se aprobó la "Guía metodológica para la elaboración de los instrumentos técnicos sustentatorios para el ordenamiento territorial" ${ }^{62}$, que incluyó la evaluación de riesgo de desastres, considerándolo como uno de los instrumentos esenciales para la concreción del Plan de Ordenamiento Territorial. Sin embargo, la guía demostró ser una inclusión incipiente, poco clara, por lo que aún no se conocen los resultados de los estudios especiales, y se ignora cómo se incorporarán en el Diagnóstico Integrado del Territorio (DIT) que prevé el Plan de Ordenamiento Territorial.

Esta situación nos enfrenta a un escenario de duplicidad, ya que, por un lado, se presenta un estudio exclusivo para la temática del cambio climático $\mathrm{y}$, por otro, se promueve acciones sectoriales

\footnotetext{
${ }^{56}\langle\mathrm{https}$ ://sinia.minam.gob.pe/documentos/tercera-comunicacion-nacional-peru-convencion-marco-las-naciones .

${ }^{57}$ Dourojeanni, 2016. <http://www.actualidadambiental.pe/?p=34799> .

${ }^{58}$ Salinas y Toribio, 2014

<http://propuestaciudadana.org.pe/sites/default/files/publicaciones/archivos/ZEE\%20Huancavelica.pdf >.

${ }^{59}$ Azpur, $2011<$ http://www.propuestaciudadana.org.pe/sites/default/files/publicaciones/archivos/cd27.pdf > .

${ }^{60}$ Capel, 2020, p. 2 <https://revistes.ub.edu/index.php/b3w/article/view/31671>.

61 D.S. No012-MINAM, 2009. Política Nacional del Ambiente <https://www.minam.gob.pe/wpcontent/uploads/2013/08/Pol\%C3\%ADtica-Nacional-del-Ambiente.pdf>.

${ }^{62}$ R.M. N ${ }^{\circ} 135-M I N A M$ <https://www.minam.gob.pe/wp-content/uploads/2014/02/rm_135-2013-minam.pdf>.
} 
similares. ¿Acaso no sería mejor integrar las acciones y así evitar las ineficiencias? Cabrera afirma que, a pesar de que el Estado ha presentado una mejoría general en su preocupación por temáticas como el ambiente, el ordenamiento territorial, el cambio climático y el desarrollo, existe un comportamiento contradictorio de su parte en cuanto a la producción de información y cartografía temática para la planificación y la toma de decisiones. Por un lado, se reparten atribuciones parciales a un abanico de instituciones y, por otro, se debilitan o destruyen otras con alta capacidad de producción multitemática y multidisciplinaria ${ }^{63}$.

Asimismo, los partidos políticos y gobiernos de turno no realizan la suficiente autocrítica sobre las políticas estatales, como, por ejemplo, una revisión del modelo económico, cuyas consecuencias intervienen directamente en la degradación ambiental. El cambio climático y sus principales causas -el sistema de transporte, industrias extractivas, excesiva generación de residuos y deforestaciónestán intrínsecamente vinculados a la tendencia creciente y lineal entre crecimiento económico y emisión de dióxido de carbono, que son equivalentes. Si bien se ha tomado una mayor conciencia en la gestión del recurso hídrico, y se han promovido esfuerzos en la Zonificación Ecológica Económica, la implicancia de esta en la toma de decisiones es casi nula. Cabrera indica que "Perú ha retrocedido en su capacidad de producción de cartografía temática e información geográfica para planificación y toma de decisiones"64, lo que corrobora Rodrigo Arce, quien destaca que "la implementación de políticas de ordenamiento territorial es débil o está prácticamente ausente"65, cuando podría ser una importante vía, una salida práctica de las políticas ambientales.

\section{Integrando gestión de riesgo, cambio climático y ordenamiento territorial}

En los últimos años se ha incrementado el interés por las políticas de ordenamiento territorial, por la adaptación al cambio climático y por la gestión de riesgos a escala internacional, identificándose como aspectos centrales en los instrumentos de manejo ambiental. Según Joaquín Farinós, la gestión de los espacios de riesgo ahora se integra en la planificación, la gobernanza y la gestión de espacios urbanos y rurales, así como también de las áreas costeras y diversas actividades ${ }^{66}$.

Con respecto a la gestión de espacios urbanos, es importante considerar que el Perú tiende hacia una concentración urbana rápida, tal como indica el Instituto Nacional de Estadística e Informática (INEI), ya que, si el año 2007 la población urbana era de 72,5\% y la rural alcanzaba el 27,5\%, una década más tarde la población urbana se ha incrementado a un 79,3\%, reduciéndose la población rural a un $20,7 \%{ }^{67}$. Por consiguiente, para reducir el impacto del fenómeno del éxodo rural se requieren planes, gobernanza y el fortalecimiento de actividades en el medio rural que permitan a sus residentes acceder a oportunidades de desarrollo, no solo de sobrevivencia, tal vez: la tierra. Además, como sugieren Villacorta y Ubeda, la administración estatal debe plantear y realizar estrategias para mitigar los efectos del cambio climático tanto en el medio rural como en el medio

63 Cabrera, 2012, p. 115 <http://www4.congreso.gob.pe/dgp/didp/boletines/02_2013/imagenes/estado/5PERUHOY2012-DESCO.pdf $>$.

${ }^{64}$ Op. cit., p. 107.

${ }^{65}$ Arce, 2013,p. 119 <https://www.ambiente.gob.ec/wp-content/uploads/downloads/2013/07/Manual_8-OTyCC.pdf>.

${ }^{66}$ Farinós, $2014<$ http://revpubli.unileon.es/ojs/index.php/poligonos/article/view/1698>.

${ }^{67}$ INEI, 2017 "Características de la Población"

<https://www.inei.gob.pe/media/MenuRecursivo/publicaciones_digitales/Est/Lib1539/cap01.pdf>. 
urbano, particularmente en las ciudades de la vertiente del Pacífico de la cordillera de los Andes, uno de los desiertos más áridos de la tierra, que es donde se concentra el $90 \%$ de la población peruana $^{68}$.

Por su parte, el geógrafo Joaquín Farinós indica que para lograr acciones eficaces, es necesario integrar nuevas metodologías en la planificación urbana que impliquen una mayor adaptación a los retos globales como el cambio climático y el aumento demográfico, en lugar de seguir con planificación parciales, segmentadas, alejadas de la participación ciudadana y, por tanto, insuficientes ${ }^{69}$. Para plantearse una imagen del territorio futuro se requiere de una actitud proactiva e integrada de los procesos de ordenamiento territorial, de la gestión del riesgo y del cambio climático, con actuaciones que tengan una capacidad de respuesta y adaptación ante los desafíos de un escenario de dinámica irreversible ${ }^{70}$. Si bien no son la regla general, en el ámbito peruano hay cierto desarrollo de iniciativas integradoras, experiencias aisladas que, según Sandra Villacorta y José Úbeda, han comenzado a generar instrumentos útiles para la ordenación del territorio, la prevención de desastres y la investigación del impacto del cambio climático ${ }^{71}$. Sin embargo, este proceso es aún lento y se requiere de una práctica más dinámica para contrarrestar efectos de gran intensidad. La institucionalidad del plan de ordenamiento territorial en el sistema de planificación nacional requiere de un dinamismo acorde a las exigencias de la situación, y no ser el proceso pausado y burocrático, sin capacidad de respuesta inmediata, que ha sido hasta la actualidad.

Carlos Rodríguez afirma que partir del conocimiento de la situación actual del clima, las proyecciones de las que se dispone y los escenarios previstos obligan a construir condiciones de desarrollo abocadas a la reducción de desastres y adaptadas a los efectos del cambio climático, insertándolo de forma conciliadora en las propuestas de ordenamiento territorial para que los órganos decisores consideren su aprobación, financiamiento e implementación ${ }^{72}$. En la misma línea, Rodrigo Arce tiene una propuesta más ambiciosa para mitigar los impactos, sugiriendo la necesaria unión de los tres procesos fundamentales, Gestión del Riesgo, Cambio Climático y Zonificación Ecológica Económica/Ordenamiento Territorial, que estarían interrelacionados ${ }^{73}$. Para gestionar eficientemente los escasos recursos que posee el Estado, es necesario abordar estos procesos desde una perspectiva integral "que permita hacer convergencia entre un enfoque biofísico que aborde las dimensiones sociales, institucionales, políticos, legales y culturales lo que es lo mismo, recoger los diferentes aspectos que conforman el desarrollo sostenible" 74 . Los tres procesos integrados conforman una posición más potente y eficaz, porque "el ordenamiento territorial y la Zonificación Ecológico Económico (ZEE) se plantean como soporte para la conservación, el uso y el aprovechamiento sostenible de los recursos naturales y la diversidad biológica, así como para la ocupación ordenada del territorio"75.

\footnotetext{
${ }^{68}$ Villacorta \& Úbeda, 2012, p. 8 <http://revistas.pucp.edu.pe/index.php/espacioydesarrollo/article/view/7580>.

${ }^{69}$ Farinós y Romero, 2008 <https://www.bage.age-geografia.es/ojs/index.php/bage/article/view/667>.

${ }^{70}$ Glave, 2009 <http://biblioteca.clacso.edu.ar/Peru/grade/20121109041114/30_glave.pdf〉.

${ }^{71}$ Op. Cit., p. 13.

${ }^{72}$ Op.cit.

${ }^{73}$ Arce, 2013, p. 12 <https://www.ambiente.gob.ec/wp-content/uploads/downloads/2013/07/Manual_8-OTyCC.pdf〉.

${ }^{74}$ Op. cit.

${ }^{75}$ Azpur, 2011, p. 28

<http://www.propuestaciudadana.org.pe/sites/default/files/publicaciones/archivos/cd27.pdf>.
} 
Cambio climático y gestión del riesgo en el proceso de ordenamiento territorial en Perú

El panorama de las acciones estatales frente al fenómeno del cambio climático es diverso y disperso. Ha habido un enorme esfuerzo en agricultura, silvicultura, pesca, salud, manejo del agua e infraestructura, pero, a falta de acciones integrales, todo ello carece de efectividad, porque las actividades operan desarticuladamente, desde diversas escalas y sectores administrativos. Como afirman Gray de Cerdán y colaboradores, sería beneficioso que las políticas relacionadas con el territorio guardasen una "estrecha vinculación entre el ordenamiento territorial, la gestión ambiental, cambio climático y la gestión del riesgo, como proceso integrado para garantizar la sustentabilidad del desarrollo territorial"76. Es prioritaria la generación de planes y enfoques integrales de gestión del territorio que consideren el impacto de los fenómenos de riesgo y el cambio climático, y que se articulen con los objetivos del ordenamiento territorial. Por consiguiente, "el desarrollo sostenible en todas sus dimensiones, la protección del medio ambiente, cambio climático y energías renovables, tienen una intransferible y fuerte implicación territorial"77.

El ordenamiento territorial y el control de riesgos son estrategias clave para la adaptación al cambio climático y la planificación del desarrollo. Para Ricardo Arias "el empleo de herramientas como los sistemas de información geográfica, facilitan los caminos para el ordenamiento territorial. Este proceso, no se podría culminar sin un escenario de confianza y trabajo con la población [...] la población debe sentirse beneficiaria y sus conocimientos son válidos"78. Por su parte, Pierre Foy opina que no basta con la integración, sino que la transversalidad que conlleva el problema climático conduce hacia una nueva mirada de los mecanismos legales e institucionales ${ }^{79}$. En el marco de una estrategia nacional, la integración de las políticas públicas necesita contar con una voluntad política y con una activa participación ciudadana, para que se superen las fallas institucionales que se traducen en dispersión y contradicciones ${ }^{80}$. El Perú es un país vulnerable al cambio climático, sin embargo, el mismo gobierno que firma tratados internacionales sobre el tema aprueba normas que afectan a las poblaciones y que colocan en serio riesgo la sostenibilidad ambiental y social.

En el año 2018 se aprobó la ley Marco sobre Cambio Climático (Ley No 30.754), estructurada en siete capítulos, que aborda las disposiciones generales sobre el objeto, sus principios y enfoques generales: 1) marco institucional para la gestión integral del cambio climático; 2) instrumentos de gestión integral para el cambio climático; 3) medidas de mitigación y adaptación al cambio climático; 4) educación, ciencia, tecnología e innovación; 5) transparencia, acceso a la información y participación ciudadana; 6) financiamiento climático, y 7) las disposiciones complementarias finales ${ }^{81}$. Los alcances de la ley son ambiciosos, pero no es suficiente, ya que presenta deficiencias en relación a la asignación de tareas, que se reparten en diversas entidades estatales, es ambigua en la definición de fuentes de financiamiento y no define claramente la entidad rectora sobre la

\footnotetext{
${ }^{76}$ Gray de Cerdán et al., 2007, p. 132

<http://www.planesmojana.com/documentos/estudios/Tempo\%20Para\%20Entregar\%20El\%20Relevo/CAPITULO\% 20III\%20ARTICULACION\%20DEL\%20ORDENAMIENTO\%20TERRITORIAL\%20Y\%20LA\%20GESTION\%2 0DE\%20RIESGOS.pdf>.

${ }^{77}$ Camacho y Melikhova, 2010, p. 177.

${ }^{78}$ Arias, 2013, p. 114

<https://pirhua.udep.edu.pe/bitstream/handle/11042/1856/MAS_PRO_001.pdf?sequence=1\&isAllowed=y>.

${ }^{79}$ Foy, 2013, p. 38 <http://revistas.pucp.edu.pe/index.php/derechopucp/article/view/6742>.

${ }^{80}$ Op. cit.

${ }^{81}$ Ley N³0754, 2018. Ley Marco sobre Cambio Climático <https://busquedas.elperuano.pe/download/url/ley-marcosobre-cambio-climatico-ley-n-30754-1638161-1>.
} 
materia, porque el Ministerio del Ambiente no ha sido capaz de llevar a cabo adecuadamente sus roles debido a su subordinación a las decisiones económicas. A todo esto se suma que en el último año la epidemia de coronavirus ha hecho que se soslaye el problema del cambio climático y ha situado en primer plano nuevos problemas, como la crisis de salud y la crisis económica derivada de las medidas de confinamiento de la población ${ }^{82}$.

\section{Consideraciones finales}

Hace ya unos años que el Perú viene enfrentando problemas medioambientales y desastres naturales relacionados con el cambio climático. Una de las numerosas evidencias son las inundaciones provocados por el fenómeno de "El Niño", cuyos resultados han sido desoladores debido al aumento de los daños. Consecuentemente, la tendencia es la incorporación de medidas de mitigación y adaptación al cambio climático, así como la gestión del riesgo, lo que implica grandes desafíos para el Estado, que se traducen en la necesidad de una mayor proactividad frente al problema a través del fortalecimiento de las instituciones públicas gestoras en la materia.

En este sentido, es urgente la búsqueda de una integralidad a través de un Plan de Ordenamiento Territorial de carácter multidimensional, dinámico y menos burocrático, que las administraciones públicas a escala nacional, regional y local puedan gestionar adecuadamente. En términos pragmáticos se requiere un compromiso coherente del Estado, en el que las medidas de mitigación y la implementación de programas estén intrínsecamente relacionados con la gestión ambiental. También es necesario que las actividades económicas extractivas reduzcan los pasivos y que se busquen mecanismos para la conservación de la biodiversidad y una adecuada gestión de recurso hídrico.

Es urgente el desarrollo e inclusión de metodologías para la incorporación de la biodiversidad y estrategias de adaptación al cambio climático dentro de los instrumentos de Zonificación Ecológica Económica (ZEE) y el Plan de Ordenamiento Territorial (POT). Simultáneamente, es necesaria la incorporación de temas estratégicos como la biodiversidad, los aspectos socioculturales, la gestión del riesgo y el manejo de cuencas, todos ellos orientados hacia un proceso de ordenamiento territorial adaptado al cambio climático. Finalmente, con el fin de reducir los impactos es importante desarrollar una diversidad de acciones colectivas como la reducción de emisiones, el ahorro de energía, el uso de energía renovables, la ocupación y uso sostenible del territorio, la concreción de los planes de ordenamiento territorial y políticas de prevención a corto, mediano y largo plazo que conduzcan a un futuro deseable.

\section{Bibliografía}

ACUERDO NACIONAL. Políticas de Estado del Acuerdo Nacional, 2012 <https://www.acuerdonacional.pe/2016/12/acta-de-la-reunion-no-116-del-foro-del-acuerdonacional/>.

AGUIRRE, Gustavo. La Valoración de los Riesgos en la Ordenación del Territorio: Metodología

${ }^{82}$ Op. Cit., p. 15. 
Cambio climático y gestión del riesgo en el proceso de ordenamiento territorial en Perú

Práctica. Boletín de La Asociación de Geógrafos Españoles, 2005, $\mathrm{n}^{\text {o }}$ 40, p. 393-406 <https://www.bage.age-geografia.es/ojs/index.php/bage/article/view/2023/1936>.

ARCE, Rodrigo. Ordenamiento Territorial y cambio climático metodología para incorporar cambio climático y gestión del riesgo de desastres en procesos de OT, 2013 <https://www.ambiente.gob.ec/wp-content/uploads/downloads/2013/07/Manual_8-OTyCC.pdf>.

ARIAS, Ricardo. Sistema de gestión de recursos culturales y naturales santuario bosque de Pomac, Lambayeque, Perú. 2013 <https://pirhua.udep.edu.pe/bitstream/handle/11042/1856/MAS_PRO_001.pdf?sequence=1\&isAl lowed $=\mathrm{y}>$.

AYESTARÁN, Ignacio. De la historia y la sociología ambientales a la ecología política: factores tecnocientíficos, sociohistóricos y ecosistémicos en la investigación sobre el cambio climático. Norba. Revista de História, $2004 \quad \mathrm{n}^{\mathrm{o}} \quad 17, \quad$ p. $111-134$ <https://dialnet.unirioja.es/servlet/articulo?codigo=1158937>.

AZPUR, Javier. Análisis de la legislación sobre planificación territorial en el Perú. 2011 <http://www.propuestaciudadana.org.pe/sites/default/files/publicaciones/archivos/cd27.pdf>.

BEBBINGTON, Antony; BURY, Jeffrey. Minería, instituciones y sostenibilidad desencuentros y desafíos. $\quad$ Anthropologica, $2010, \quad \mathrm{n}^{\mathrm{o}} \quad 28, \quad$ p. $\quad$ 53-84 $<$ https://dialnet.unirioja.es/servlet/articulo?codigo=5042120>.

BIELZA DE ORY, Vicente. Organización y ordenamiento del territorio. Desarrollo y sostenibilidad. Experiencia europea para el Perú. Revista Geográfica, 2012, n 152, p. 83-103 $<$ https://www.jstor.org/stable/43558256?seq=1>.

CABRERA, Teresa. Perú Hoy, Lo urbano en el Perú. (DESCO, Ed.), Roble Rojo Grupo de negocios, $\quad$ SAC. 2012 <http://www4.congreso.gob.pe/dgp/didp/boletines/02_2013/imagenes/estado/5-PERUHOY2012DESCO.pdf>.

CAMACHO, José; MELIKHOVA, Yulia. Perspectiva territorial de la Unión Europea: El largo camino hacia la cohesión territorial. Cuadernos Geográficos, 2010, vol. 2, nº 47, p. 169-188.

CAPEL, Horacio. Acción política y ciudadana para frenar el cambio climático. Biblio3W, Revista Bibliográfica de Geografía y Ciencias Sociales. Barcelona: Universidad de Barcelona, 5 de agosto de 2020, vol. XXV, nº 1.303 <https://revistes.ub.edu/index.php/b3w/article/view/31671>.

CUESTA, María. Ordenación del territorio, medio ambiente y globalización: Reflexiones desde la geografía regional al nuevo contexto socio-económico. Boletín de La Asociación de Geógrafos Españoles, 2006, $\quad \mathrm{n}^{\mathrm{o}} \quad 42, \quad$ p. $\quad 255-269 \quad<$ https://www.bage.agegeografia.es/ojs/index.php/bage/article/view/575>.

DE ECHAVE, José; HOETMER, Raphael; PALACIOS, Mario. Minería y territorio en el Perú. 
Conflictos, resistencias y propuestas en tiempos de globalización. Lima - Perú, Fondo editorial de la Facultad de Ciencias Sociales, 2009 <http://cooperaccion.org.pe/publicaciones/mineria-yterritorio-en-el-peru-conflictos-resistencias-y-propuestas-en-tiempos-de-globalizacion/>.

DOUROJEANNI, Marc. ¿Existe planificación en el Perú?, 2016 <http://www.actualidadambiental.pe/?p=34799>.

FARINÓS, Joaquín. Ordenación del Territorio desde la Geografía. De renovaciones conceptuales, retos, amenazas y espacios de oportunidad. Polígonos. Revista de Geografía, 2014, nº 26, p.17-58 <http://revpubli.unileon.es/ojs/index.php/poligonos/article/view/1698>.

FARINÓS, Joaquín; ROMERO, Juan. La gobernanza como método para encarar los nuevos grandes retos territoriales y urbanos. Boletín de la Asociación de Geógrafos Españoles, 2008, $\mathrm{n}^{\circ}$ 46, p. 5-9 <https://www.bage.age-geografia.es/ojs/index.php/bage/article/view/667>.

FOY, Pierre. Estimativas y prospectivas sobre el sistema jurídico ambiental peruano post-Río + 20. Revista de La Facultad de Derecho, 2013, n ${ }^{\circ}$ 70, p. 25-44. <http://revistas.pucp.edu.pe/index.php/derechopucp/article/view/6742>.

FRANCISKOVIC, Millitza y GODENZI, Jorge. Los primeros intentos de institucionalidad ambiental en el Perú y su precario desarrollo. Revista Vox Juris, 2014, vol. 27, nº. 1, p. 239-260. $<$ https://repositorio.usmp.edu.pe/handle/20.500.12727/1010>.

FRANCO Eduardo; ZILBERT, Linda. El sistema nacional de defensa civil en el Perú o el problema de la definición del campo de los desastres. En LAVELL, Allan, FRANCO, Eduardo. Estado, sociedad y gestión de los desastres en américa latina- en busca del paradigma perdido. Lima: Red de Estudios Sociales en Prevención de Desastres en América Latina, 1996, p. 1-109.

GLAVE, Manuel. Ordenamiento Territorial y desarrollo en el Perú: Notas conceptuales y balance $\begin{array}{llll}\text { de } & \text { logros } & \text { y } & \text { limitaciones, }\end{array}$ <http://biblioteca.clacso.edu.ar/Peru/grade/20121109041114/30_glave.pdf>.

GRAY DE CERDÁN, Nelly; QUIROGA DE BENEGAS, Silvia y CAD, María. Articulación del Ordenamiento Territorial y la Gestión del Riesgo. CRID - Centro Regional de Información sobre Desastres para América Latina y el Caribe, 2007 <http://www.planesmojana.com/documentos/estudios/Tempo\%20Para\%20Entregar\%20El\%20Re levo/CAPITULO\%20III\%20ARTICULACION\%20DEL\%20ORDENAMIENTO\%20TERRITO RIAL\%20Y\%20LA\%20GESTION\%20DE\%20RIESGOS.pdf $>$.

MARIÑO, Jersy; RIVERA, Marco; THOURET, Jean; CACYA, Lourdes; SIABE, Claus; CHÁVEZ, Antonio; SALAS, Guido y ZÚÑIGA, Sebastian. Evaluación de peligros volcánicos y elaboración del mapa de peligros del volcán Misti (Arequipa), 2006 <https://repositorio.ingemmet.gob.pe/bitstream/20.500.12544/441/2/Evaluacion_de_peligros_vol canicos_mapa_de_peligros_volcan_Misti.pdf >.

MARTÍN Antonio y MERINERO Rafael. Planificación estratégica territorial. Estudios 
Cambio climático y gestión del riesgo en el proceso de ordenamiento territorial en Perú

metodológicos. Sevilla, España: Universidad Pablo de Olavide, 2010 <https://www.sistemamid.com/panel/uploads/biblioteca/7097/7128/7129/83506.pdf>.

MAYO, Adriana. Cinco cordilleras del Perú desaparecerán en los próximos 20 años. Diario $L a$ República, Perú, 31 julio 2016 <https://ambiental.net/2016/08/perdida-de-glaciares-por-cambioclimatico-en-peru/>.

MEDRANO, Luis. Estrategia de comunicación y educación de apoyo a la zonificación económica ecológica para el Ordenamiento Territorial la región de Cajamarca, 2008 $<$ https://zeeot.regioncajamarca.gob.pe/sites/default/files/EstComunicacionZEEOT.pdf>.

MENDOZA, Armando; PASSUNI, Silvia; DE ECHAVE, José. La Minería en el Sur Andino: El caso de Cusco, 2006 <https://redextractivas.org/download/la-mineria-en-el-sur-andino-el-caso-decusco-cooperaccion-2015/>.

MINISTERIO DEL AMBIENTE. Plan de acción de adaptación y mitigación frente al cambio climático, $2010<$ https://sinia.minam.gob.pe/documentos/plan-accion-adaptacion-mitigacionfrente-cambio-climatico $>$.

MINISTERIO DEL AMBIENTE. Ordenamiento Territorial (OT) en el Perú (2011-2015). Lima; Ministerio del Ambiente, 2016 <https://sinia.minam.gob.pe/documentos/ordenamiento-territorialot-peru-2011-2015>.

RENDON, Sisko. Ordenamiento y planificación territorial en Perú. Una aproximación critica a los instrumentos de zonificación ecológica y económica (ZEE). Tesis Doctoral, Universidad de Barcelona, 2019. http://hdl.handle.net/10803/668162.

RODRÍGUEZ, Carlos. Ordenamiento Territorial y Gestión del riesgo. La Antigua- Guatemala: AECID y DEMUCA, 2009 <https://docplayer.es/8763900-Modulo-3-ordenamiento-territorial-ygestion-del-riesgo.html>.

SALINAS, Emerson y TORIBIO, Sonia. Zonificación ecológica económica de la región Huancavelica-Avances, utilidad y pasos a seguir. Lima: DESCO-Grupo Propuesta, Ed., 2014 $<$ http://propuestaciudadana.org.pe/sites/default/files/publicaciones/archivos/ZEE\%20Huancavelic a.pdf $>$.

SOCIEDAD DE URBANISTAS DEL PERÚ. Informe Perú: vulnerabilidad de las ciudades frente al cambio climático en agua y saneamiento, 2011. Lima: SUP $<$ https://sinia.minam.gob.pe/documentos/informe-peru-vulnerabilidad-las-ciudades-frentecambio-climatico-agua>.

VILLACORTA, Sandra y ÚBEDA, José. El mapa geomorfológico de Lima Metropolitana y sus cuencas hidrográficas, una herramienta para la gestión sostenible del territorio. Espacio y

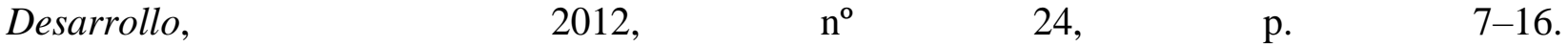
$<$ http://revistas.pucp.edu.pe/index.php/espacioydesarrollo/article/view/7580>. 
ZAAR, Miriam. Cambio climático antropogénico y decrecimiento. Ar@cne. Revista Electrónica de Recursos de Internet sobre Geografía y Ciencias Sociales. Barcelona: Universidad de Barcelona, 1 de enero de 2021, vol. XXV, $\mathrm{n}^{\circ}$ 250. DOI: https://doi.org/10.1344/ara2021.250.33232.

ZUCCHETTI, Anna, RAMOS, Victoria, ALEGRE, Marcos, AGUILAR, Zenón, ARROYO, Roberto y TRIBUT, Eric. Guía Metodológica para el Ordenamiento Territorial y la Gestión de Riesgos para Municipios $\quad y \quad$ Regiones, 2008 <http://www.observatorioubogrd.cl/descargas/MANUAL\%20PARA\%20MUNICIPIOS\%20EN\% 20GRD.pdf>.

Ficha bibliográfica:

RENDÓN-CUSI, Sisko. Cambio climático y gestión del riesgo en el proceso de ordenamiento territorial en Perú. Ar@cne. Revista Electrónica de Recursos de Internet sobre Geografia y Ciencias Sociales. Barcelona: Universidad de Barcelona, I de diciembre de 202I, vol. XXV, $n^{\circ} 261$. DOI: https://doi.org/I0.1344/ara2021.26I.36958

\section{Menú Geo Crítica}

